\title{
Taç eterlerin metal iyonları ile kompleksleşmesinin kondüktometriye Job's Plot yönteminin uygulanmas1 ile belirlenmesi
}

\author{
Ümit ÇALIŞIR ${ }^{1}$, Baki ÇIÇEK ${ }^{2, *}$ \\ ${ }^{1}$ Balıkesir Üniversitesi Fen Bilimleri Enstitüsü Kimya Anabilim Dalı, Çă̆̆ls Kampüsü, Balıkesir. \\ ${ }^{2}$ Balıkesir Üniversitesi Fen Edebiyat Fakültesi Kimya Bölümü, Çağış Kampüsü, Balıkesir.
}

Geliş Tarihi (Received Date): 02.09.2019

Kabul Tarihi (Accepted Date): 18.09.2019

\section{Özet}

Bu çalışma kapsamında benzo-tiyo ve benzo-okso taç eterler ile metal iyonları arasındaki iyon-dipol etkileşmeleri Job's Plot yönteminin kondüktometriye uyarlanmasiyla belirlendi (Çözücü sistemi: \%50 Asetonitril/su). Daha önce verilen mikrodalga sentez yöntemi kullanilarakyeniden sentezlenen U1 (bis (1,2-dibenzo) oktatiyo tetrakarbonil-29crown-6), U2 (bis(1,2-dibenzo) tetratiyo tetrakarbonil-29-crown-6) taç eterlerinin $\mathrm{NaCl}$, $\mathrm{KCl}, \mathrm{MgCl}, \mathrm{CaCl}_{2}, \mathrm{ZnCl}_{2}, \mathrm{FeSO}_{4}, \mathrm{AgNO}, \mathrm{CoCl}_{2}$ metal tuzlarlyla komplesleşmeleri incelendi. Taç eter-katyon kompleksinin kompleksleşme oranı, kompleksleşme sabiti $\left(\mathbf{K}_{\mathbf{e}}\right)$ ve Serbest Gibbs Enerjisi $\left(\mathbf{\Delta G}^{\boldsymbol{\theta}}\right)$ hesapland. Kondüktometri ile gerçekleştirilen çalışmalara göre $\mathbf{U 1}$ bileşiği için kompleksleşme sabiti $\mathrm{Na}^{+}>\mathrm{Zn}^{2+}>\mathrm{Ca}^{2+}>\mathrm{Ag}^{+}>\mathrm{K}^{+}>$ $\mathrm{Mg}^{2+}>\mathrm{Co}^{2+}>\mathrm{Fe}^{2+}$ yönünde azalırken, U2 bileşiği için $\mathrm{Zn}^{2+}>\mathrm{Fe}^{2+}>\mathrm{Na}^{+}>\mathrm{K}^{+}>\mathrm{Co}^{2+}>$ $\mathrm{Ag}^{+}>\mathrm{Ca}^{2+}>\mathrm{Mg}^{2+}$ yönünde değiştiği gözlemlenmiştir. Bu çalışma sonuçlarına göre taç eterler metal sensörü, biyoorganizmalardaki enzimler için inhibitör veya aktivatör ve sanayi-çevre uygulamalarında metal iyonlarının giderimi için kullanılabilirler.

Anahtar kelimeler: Kondüktometri, kompleks oluşum sabiti, kompleksleşme sabiti, Job's Plot yöntemi.

Ümit ÇALIŞIR, umitcalisir@siirt.edu.tr, http://orcid.org/0000-0001-7699-2008.

*Baki ÇIÇEK, bcicek@balikesir.edu.tr, http://orcid.org/0000-0003-1257-1188. 


\title{
Determination of crown ether complexation with metal 1ons by application Job's Plot method to conductometry
}

\begin{abstract}
In this study, ion-dipole interactions between benzo-thio and benzo-oxo crown ethers and metal ions were determined by adaptation of Job's Plot method to conductivity (Solvent system: 50\% Acetonitrile / water). The complexation properties of the crown ethers previously synthesized using microwave synthesis method (U1 (bis (1,2-dibenzo) octathio tetracarbonyl-29-crown-6), U2 (bis (1,2-dibenzo) tetrathio tetracarbonyl-29-crown-6)) and salts ( $\mathrm{NaCl}, \mathrm{KCl}, \mathrm{MgCl} 2, \mathrm{CaCl}_{2}, \mathrm{ZnCl}_{2}, \mathrm{FeSO}_{4}, \mathrm{AgNO}_{3}, \mathrm{CoCl}_{2}$ ) were investigated. The complexation rate, complexation constant (Ke) and Free Gibbs Enthalpy $\left(\Delta G^{\theta}\right)$ of the crown ether-cation complex were calculated. According to the studies carried out by conductometry, the complexation constant for the compound U1 decreased in the direction $\mathrm{Na}^{+}>\mathrm{Zn}^{2+}>\mathrm{Ca}^{2+}>\mathrm{Ag}^{+}>\mathrm{K}^{+}>\mathrm{Mg}^{2+}>\mathrm{Co}^{2+}>\mathrm{Fe}^{2+}$, while for the U2 compound $\mathrm{Zn}^{2+}>\mathrm{Fe}^{2+}>\mathrm{Na}^{+}>\mathrm{K}^{+}>\mathrm{Co}^{2+}>\mathrm{Ag}^{+}>\mathrm{Ca}^{2+}>\mathrm{Mg}^{2+}$ were observed. According to the results of this study, selected crown ethers can be used for metal sensor, inhibitor or activator for enzymes in bioorganisms and metal trap in industrial-environmental applications.
\end{abstract}

Keywords: Conductometry, complex formation constant, complexation constant, Job's Plot method.

\section{Giriş}

Makro halkalı bileşiklerin bir üyesi olarak taç eterler 1960'lı y1llardan beri bilinmektedir [1-4]. İçermiş oldukları hidrojen ve karbon atomlarından oluşan bir hidrofobik dış kavite ile apolar karakter gösterirken, oksijen, kükürt, azot gibi elementlerin birini ya da birkaçını içermesi durumlarından kaynaklı hidrofilik polar bir iç kaviteye sahiptir [5]. Bu polar iç kavitesi sayesinde katyonlarla kararlı kompleksler oluşturmaktadır. İçermiş olduğu oksijen, azot ve kükürt atomları halkaya faklı katyonları bağlama özelliği sunmaktadır [6,7]. Örneğin oksijen içeren analogları daha çok sert metallerin katyonlarını bağlarken, kükürt ve azot bu ilgiyi yumuşak olarak nitelendirilen katyonlara yönlendirmektedir. Aynı zamanda taç eterler bu iç kavite sayesinde çoklu katyon içeren ortamlardan bazı metallerle seçimli olarak kompleks yapabilmektedir [8-12]. Bu seçimli kompleksleşme metal afinitesi olarak tanımlanmakla birlikte halka üzerindeki $\mathrm{S}$, $\mathrm{O}$ ve $\mathrm{N}$ atomlarının kombinasyonu ile yumuşak/sert katyonlarını aynı anda seçimli bağlayan sistemler tasarlanabilmektedir [13-17]. Taç eterlerin metallerle olan kararlı kompleksleri taç eterleri metal uzaklaştırma ajanı olarak kullanılabilmesi taç eterlere ayrı bir boyut kazandırmıştır [18]. Kondüktometri çok düşük derişimlerde çalışma, hızlı yanıt süresi, pratik olması gibi imkânlar sunarken potansiyometrik çalışmalara göre çoklu element sistemlerinde kompleksleşme seçiciliğinin belirlenmesine olanak sağlamamaktadır $[19,20]$. Ortamdaki toplam iletkenlik üzerinden değerlendirmeler yapmaya imkân sağlamaktadır. İkili sulu-çözücülü sistemler kimya sektöründe oldukça fazla kullanım alanlarına sahiptir [10,21]. Bu sistemlerin biyokimyadan biyofizik anabilim dallarına birçok kullanımı mevcuttur. Bu amaçla birçok su ile karışabilen çözücü (asetonitril, dioksan, etanol, metanol, DMSO vb.) kullanılabilmektedir [22,23]. Sürekli değişimler yöntemi 1928 yılında Job tarafından sunulduğundan Job's Plot yöntemi adıyla da 
bilinmektedir [24]. M ve L gibi iki türün bulunduğu çözeltilerde, $M$ türü $B$ ile bağlanabilir. Bazı durumlarda, birden fazla $M$ tek bir L'ye bağlanır. L'ye bağlanma miktarını (bağlanma stokiyometrisi) belirlemenin yöntemlerinden birisi Job's Plot grafiği kullanmaktır. Günümüzde analitik kimya ve biyokimyada sık sık kullanılmaktadır [2527]. Job's Plot yöntemi genellikle Kompleksleşmeyi yapan bileşiklerden birinin mol kesrine karşılık UV absorbansının grafik edilmesiyle belirlenmektedir [27]. Bu çalışmada grubumuzca daha önceki çalışmamızda sentezlenen bileşikler [16] kullanılarak kondüktometri yönteminin Job's Plot üzerine uygulanmasıyla kompleksleşme oranı ve sabitlerinin belirlenmesi çalışmaları yapılmıştır. Yaklaşık aynı halka boyutuna sahip taç eterlerin farklı heteroatom kombinasyonları seçilerek farklı yarıçapa ve sertliklere sahip katyonları bağlamak hedeflenmiştir.

\section{Deneysel çalışmalar}

\subsection{Kullanilan cihazlar ve kimyasal malzemeler}

Bu çalışmada kullanılan tuzlar ticari olarak (Sigma Aldrich, Carlo Erba, Merck, Roth) yüksek saflıklarda ( $\geq \%$ 98.5) temin edilmiştir. Sulu çözeltiler hazırlanırken Human Corporation marka New Human Power I S-UV model ultra saf su cihazından üretilen $18.3 \mathrm{M} \Omega / \mathrm{cm}$ dirençte ultra saf su kullanılmıştır. Çözücü sistemi (\%50 Asetonitril/su) hazırlanırken HPLC saflıkta (Sigma Aldrich, gradient grade $\geq \%$ 99.9) Asetonitril kullanılmıştır. Deneylerde hassas terazi (KERN ABJ $(\mathrm{d}=0.1 \mathrm{mg})$ ), otomatik pipet (ErgOne ve Brand), dispanser (Brand marka 0,5-5 mL ve 1-10 mL), ultrasonik banyo (Bandolin), manyetik karıştırıcı (IKA C-MAG HS-7), pH metre (Hanna HI 2211, probu HI1131), kondüktometre (Mettler Toledo SevenCompact Conductivity S230 ve Mettler Toledo InLab 741 ISM elektrot) kullanılmıştır.

\subsection{Benzo-tiyo ve benzo-okso taç eterlerin sentezi}

Çalışma kapsamında kullanılan taç eterler mikrodalga sentez yöntemiyle daha önceki çalışmalarımızda verilen prosedürlere göre sentezlenmiştir. Sentezlenen U1 (bis(1,2dibenzo) oktatiyo tetrakarbonil-29-crown-6) benzo-tiyo taç eteri ve U2 (bis(1,2-dibenzo) tetratiyo tetrakarbonil-29-crown-6) benzo-okso taç eteri çalışmada kullanılmıştır [16].

\subsection{Kondüktometrik yöntem}

$\mathrm{Bu}$ çalışma kapsamında gerçekleştirilen tüm deneyler $25^{\circ} \mathrm{C}$ 'deki sıcaklık hücresinde gerçekleştirilmiştir. Kompleksleşmesi belirlenecek çözelti karışımı $10 \mathrm{~mL}$ balon jojede hazırlanarak iletkenlik hücresine alınmıştır. İçerisine homojen dağılımın gerçekleşebilmesi amacıyla manyetik balık ilave edilerek çözeltinin sabit sıcaklığa ulaşması amacıyla 3 dakika sabit hızda karıştırılmıştır. İçerisine elektrot daldırılarak yine sıcaklığın dengeye ulaşması için 2 dakika beklenilmiştir. Beşinci dakikanın sonunda art arda 10 ölçüm alınmıştır. Çalışma tekrarlı olarak gerçekleştirilmiş ve sonuçların ortalaması hesaplamalarda kullanılmıştır [17,19-21,28].

\section{Sonuçlar ve tartışma}

Bu çalışma kapsamında benzo-tiyo ve benzo-okso taç eterler ile metal iyonları arasındaki iyon-dipol etkileşmeleri Job's Plot yönteminin kondüktometriye uyarlanmasıyla belirlendi (Çözücü sistemi: \%50 Asetonitril/su). Kompleksleşme oranı, Kompleksleşme sabiti, serbest Gibbs enerjisi gibi iletkenlik parametreleri hesaplandı. Önceden klasik ve 
mikrodalga sentez yöntemleriyle sentezlenen, sıvı-sıvı iyon çiftleri metal ekstraksiyonu ile metal seçicilikleri belirlenen bileşiklerin, U1 (bis(1,2-dibenzo) oktatiyo tetrakarbonil29-crown-6), U2 (bis(1,2-dibenzo) tetratiyo tetrakarbonil-29-crown-6), $\mathrm{NaCl}, \mathrm{KCl}$, $\mathrm{MgCl}_{2} .6 \mathrm{H}_{2} \mathrm{O}, \mathrm{CaCl}_{2} .2 \mathrm{H}_{2} \mathrm{O}, \mathrm{ZnCl}_{2}, \mathrm{FeSO}_{4} .7 \mathrm{H}_{2} \mathrm{O}, \mathrm{AgNO}_{3}, \mathrm{CoCl}_{2} .8 \mathrm{H}_{2} \mathrm{O}$ metal tuzlariyla kondüktometrik yöntemle kompleksleşmeleri incelenmiştir (Şekil 1) [16].

Kondüktometrik olarak gerçekleştirilen çalışmada elde edilen veriler kullanılarak Tablo 1 'de verilen kompleksleşme oranı, kompleksleşme sabiti ve serbest Gibbs enerjisi 1-3 denklemleri kullanılarak hesaplanmıştır [19]. Buna göre kompleksleşme denklemi (1) şu şekildedir;

$a M^{m+}+b L \rightleftharpoons M_{a} L_{b}^{m+}$

$\mathrm{Bu}$ denkleme göre $\mathrm{M}^{\mathrm{m}+}$, L sirasıyla katyon, ligandı simgeler. Bunun sonucu olarak farklı oranlarda kompleks oluşumu için $\mathrm{K}_{\mathrm{e}}$ denge sabiti (2) ile yazılabilir.

$K_{e}=\frac{M_{a} L_{b}^{m+}}{\left[M^{m+}\right]^{a}[L]^{b}}$

Ayrıca kompleksleşme oranı ise denge anındaki tuzun miktarının ligandın miktarına oranı hesaplanarak elde edilir (3) [24]. Burada $n_{M}$ tuzun mol sayıs1 ve $n_{L}$ ise ligantın mol sayısidır.

Kompleksleşme Oranı $=\frac{n_{M}}{n_{L}}$

(1) nolu denklem U1 ve U2 taç eterlerine uygulandığında, ayrıntılı kompleksleşme mekanizması şu şekilde çizilebilir (Şekil 1).

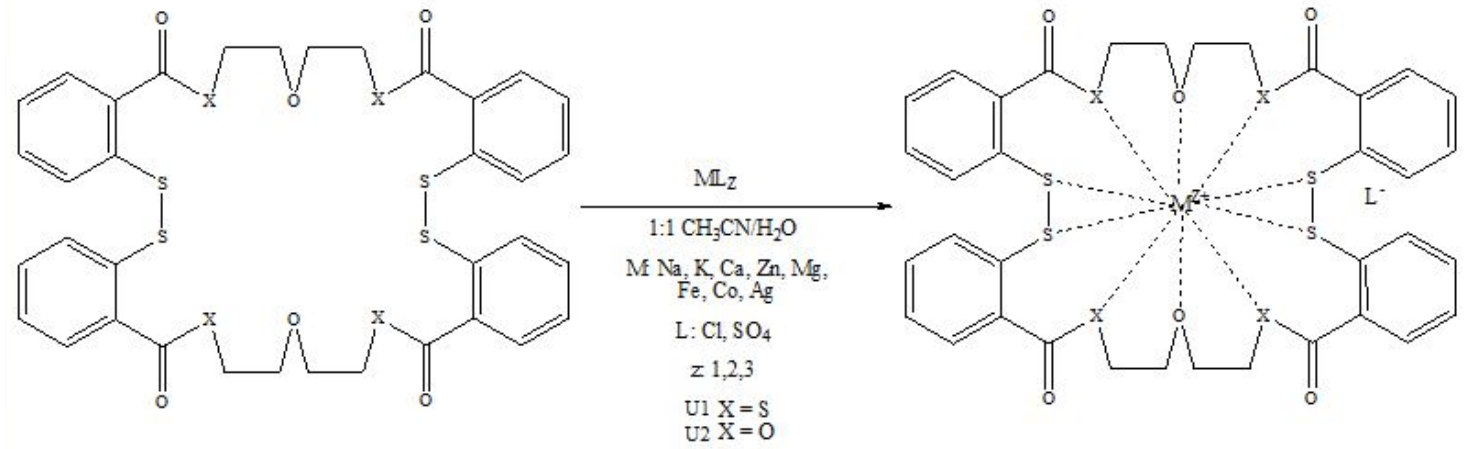

Şekil 1. U1 ve U2 benzo tiyo ve benzo okso taç eterleri ile metal tuzlarının \% 50 asetonitril/saf su içerisinde kompleksleşmeleri

$\mathrm{U} 1$ ve $\mathrm{U} 2$ taç eterleri ile $\mathrm{NaCl}, \mathrm{KCl}, \mathrm{MgCl}_{2} .6 \mathrm{H}_{2} \mathrm{O}, \mathrm{CaCl}_{2} .2 \mathrm{H}_{2} \mathrm{O}, \mathrm{ZnCl}_{2}, \mathrm{FeSO}_{4} .7 \mathrm{H}_{2} \mathrm{O}$, $\mathrm{AgNO}_{3}, \mathrm{CoCl}_{2} .8 \mathrm{H}_{2} \mathrm{O}$ metal tuzlarının iletkenlik verileri kullanılarak kompleksleşme oranı ve kompleksleşme grafikleri (Şekil 2-9 a-b-c) elde edilmiştir. 


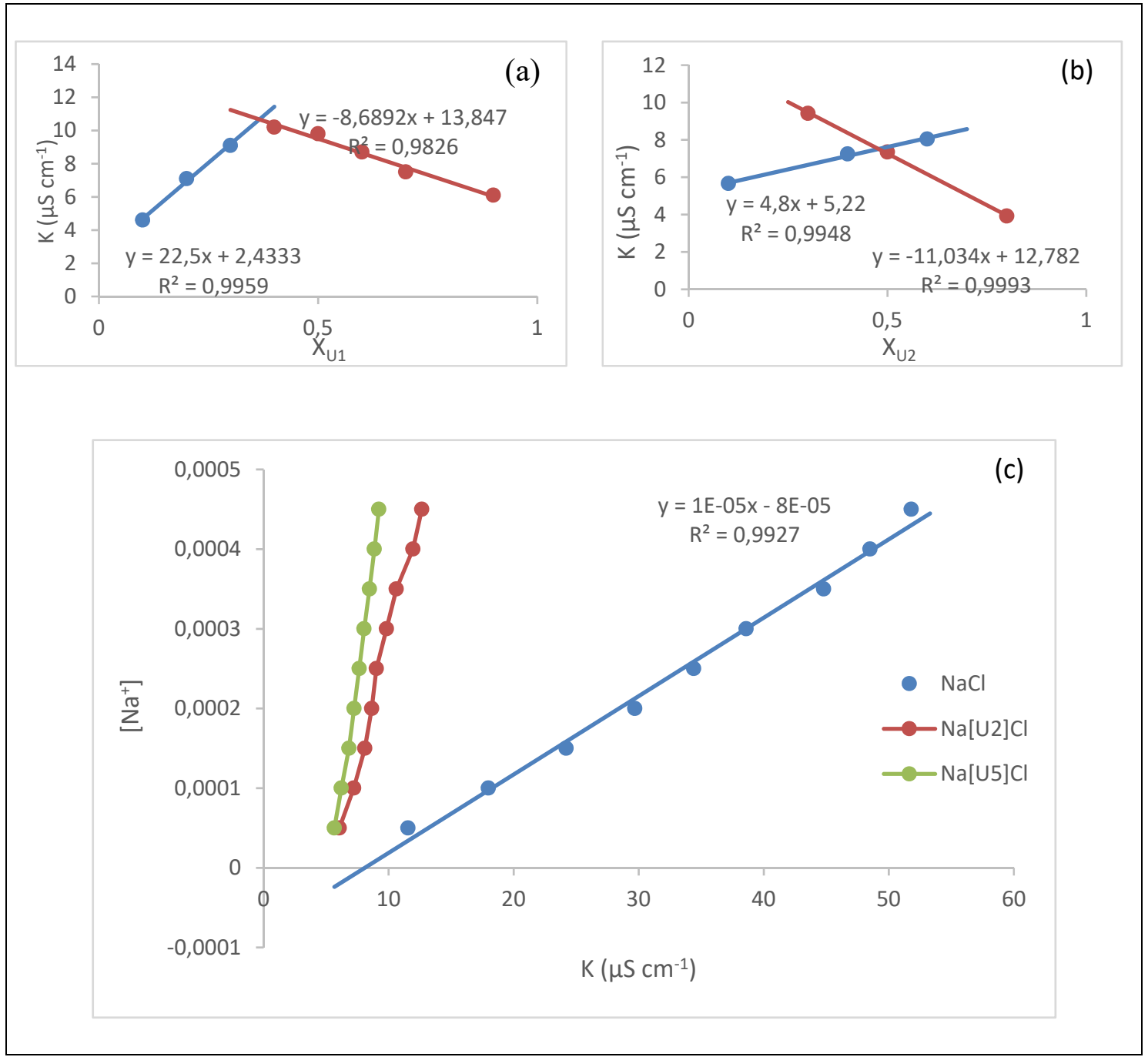

Şekil 2. $25{ }^{\circ} \mathrm{C}$ da \% 50 asetonitril/su içerisinde (a) U1 ligantının, (b) U2 taç eterinin sodyum iyonu ile kompleksleşme oranının tespit edilmesi, (c) $\mathrm{NaCl}$ ile $U 1$ ve $U 2$ kompleksleri için gözlenen iletkenlik $\left(\mathrm{K}\left(\mu \mathrm{S} \mathrm{cm}^{-1}\right)\right)$ karşı $\left[\mathrm{Na}^{+}\right]\left(\mathrm{mol} \mathrm{L}^{-1}\right)$ iyonu değişimi grafikleri

Şekil 2 incelendiğinde sodyum klorür tuzu ile U1 ve U2 taç eterlerinin kompleksleşme oranları (tuz/ligand) sırasıyla 3/2 ve 1/1 olarak tespit edilmiştir (Tablo 1). Bu durum U1 tiyo taç eterinin diğer okso taç etere göre daha çok kükürt atomu içermesinden kaynaklanmaktadır. Kükürt atomları taç eter içerisinde hacimli olmaları sebebiyle halka dışına doğru yönlenmiştir. Oldukça küçük bir iyon çapına sahip olan sodyum iyonu okso taç eterin iç halka kavitesine tam 1/1 yerleşirken, U2 taç eteri sandviç kompleks yapmaktadır. Nispeten küçük iyon çapı, küçük iyon yükü sodyum ile kompleskleşmeyi artırmıştır. Her iki taç eter de neredeyse en çok kompleksleşmeyi sodyum iyonu ile yapmıştır. Son olarak şekil $2 \mathrm{c}$ incelendiğinde artan konsantrasyonla doğru orantılı olarak komplekleşmenin arttı̆̆ı gözlenmiştir. 


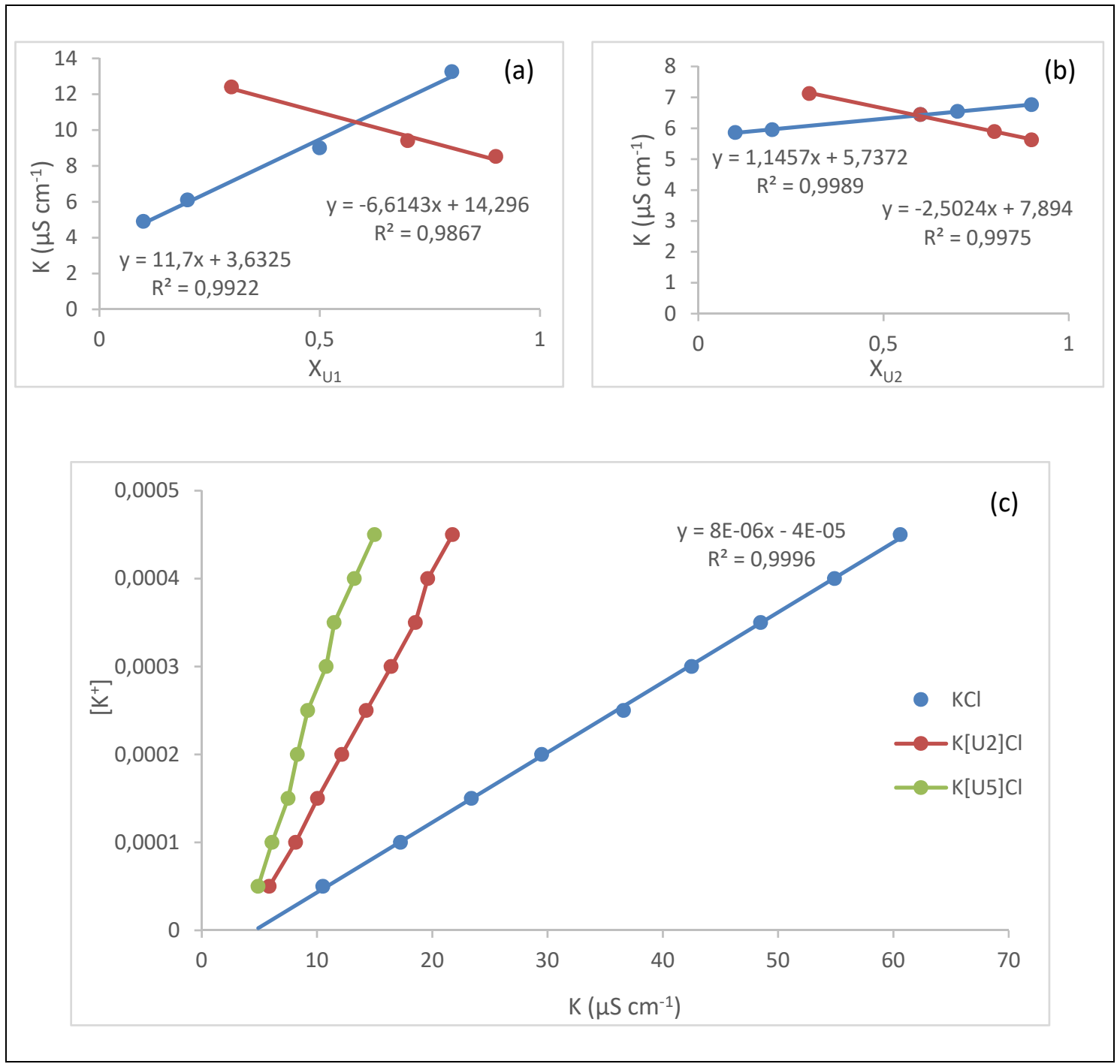

Şekil 3. $25{ }^{\circ} \mathrm{C}$ da $\% 50$ asetonitril/su içerisinde (a) U1 ligantının, (b) U2 taç eterinin potasyum iyonu ile kompleksleşme oranının tespit edilmesi, (c) $\mathrm{KCl}$ ile $U 1$ ve $U 2$ kompleksleri için gözlenen iletkenlik $\left(\mathrm{K}\left(\mu \mathrm{S} \mathrm{cm}^{-1}\right)\right)$ karşı $\left[\mathrm{K}^{+}\right]\left(\mathrm{mol} \mathrm{L}^{-1}\right)$ iyonu değişimi grafikleri

Potasyum klorür tuzunun U1 ve U2 taç eterleriyle yapmış oldukları kompleksler incelendiğinde oluşan komplekslerin kompleksleşme oranlarının aynı oldu görülmektedir (2/3). Elde edilen kompkesleşme oranlarının kompleksleşme sabiti Ke'nin hesabında kullanılmasıyla oldukça yüksek kompleksleşmenin oluştuğu tespit edilmiştir (logKe, U1:14; U2:19). Ayrıca şekil 3c'de verilen kompleksleşme grafiği iki taç eter arasındaki kompleksleşmeyi karşılaştırmamıza olanak sağlamaktadır. Buna göre kükürt oranı az olan ve okso taç eter özelliği taşıyan U2 taç eteri diğer tiyo taç eterden daha yüksek kompleksleşmeye sahiptir. 


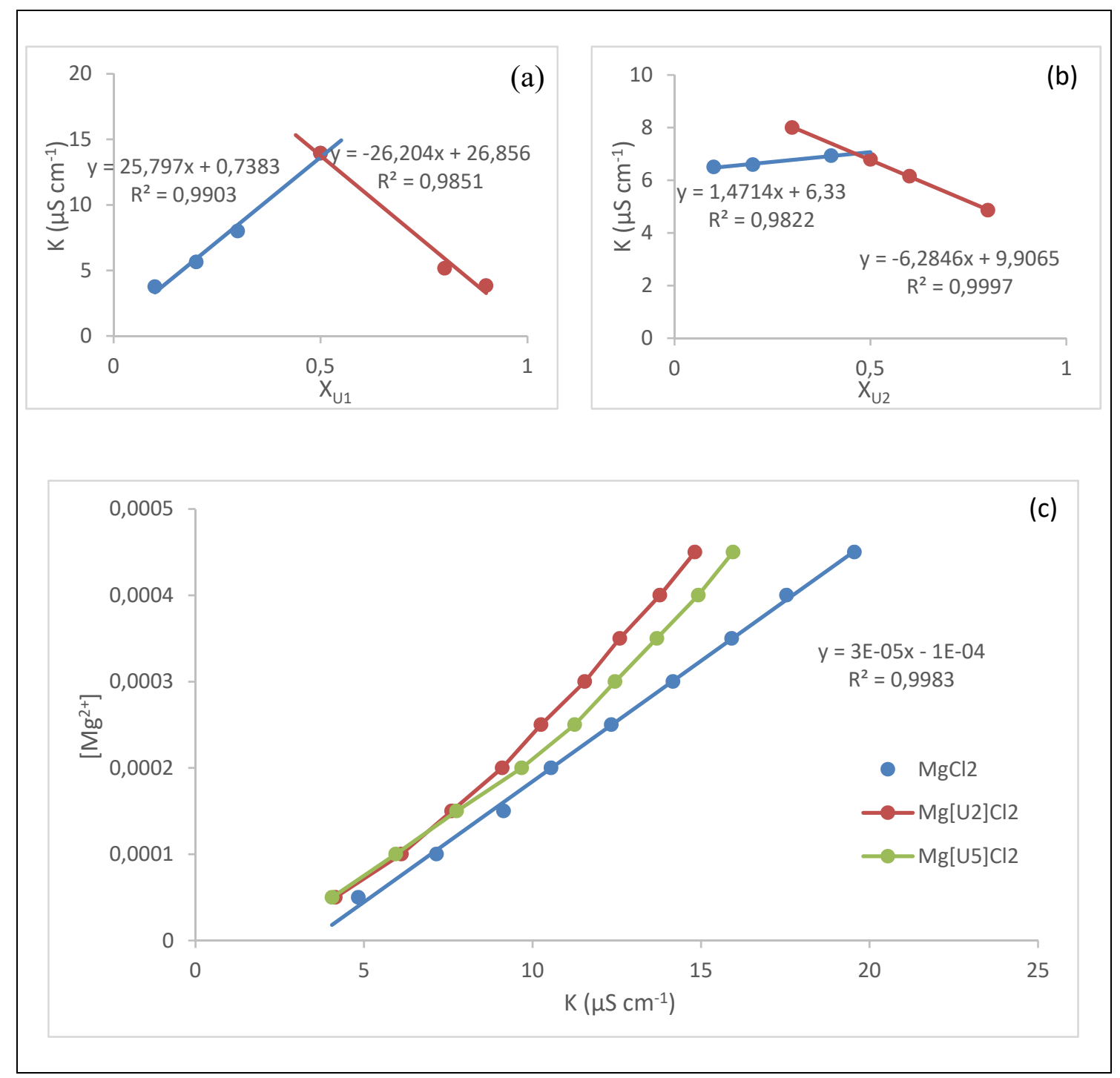

Şekil 4. $25{ }^{\circ} \mathrm{C}$ da $\% 50$ asetonitril/su içerisinde (a) U1 ligantının, (b) U2 taç eterinin magnezyum iyonu ile kompleksleşme oranının tespit edilmesi, (c) $\mathrm{MgCl}_{2}$ ile $U 1$ ve $U 2$ kompleksleri için gözlenen iletkenlik $\left(\mathrm{K}\left(\mu \mathrm{S} \mathrm{cm}^{-1}\right)\right)$ karş1 $\left[\mathrm{Mg}^{2+}\right]\left(\mathrm{mol} \mathrm{L}^{-1}\right)$ iyonu değişimi grafikleri

Artan ligant konsantrasyonuna karşılık azalan tuz konsantrasyonunun kompleskleşmelerinin incelenmesiyle elde edilen kompleksleşme oranlarına göre (Şekil 4 a-b) tuz/ligand kompleksleşme oranları hem U1 hem de U2 taç eterleri için 1/1 olarak belirlenmiştir. Tablo 1 incelendiğinde $\mathrm{Mg}^{2+}$ iyonu ile hem $\mathrm{U} 1$ hem de $\mathrm{U} 2$ taç eterlerinin diğer iyonlara kıyasla daha az kompleksleşme gösterdiği görülmektedir (log Ke değerleri; U1: 6.36; U2: 4.94). Ancak daha ayrıntılı kompleksleşmelerine bakıldığında (Şekil 4c) yüksek konsantrasyonlarda kompleksleşmenin arttığ 1 ve tiyo taç eter olan U1 taç eterinin U2 taç eterine göre daha yüksek kompleksleşmeye sahip olduğu gözlenmektedir. 


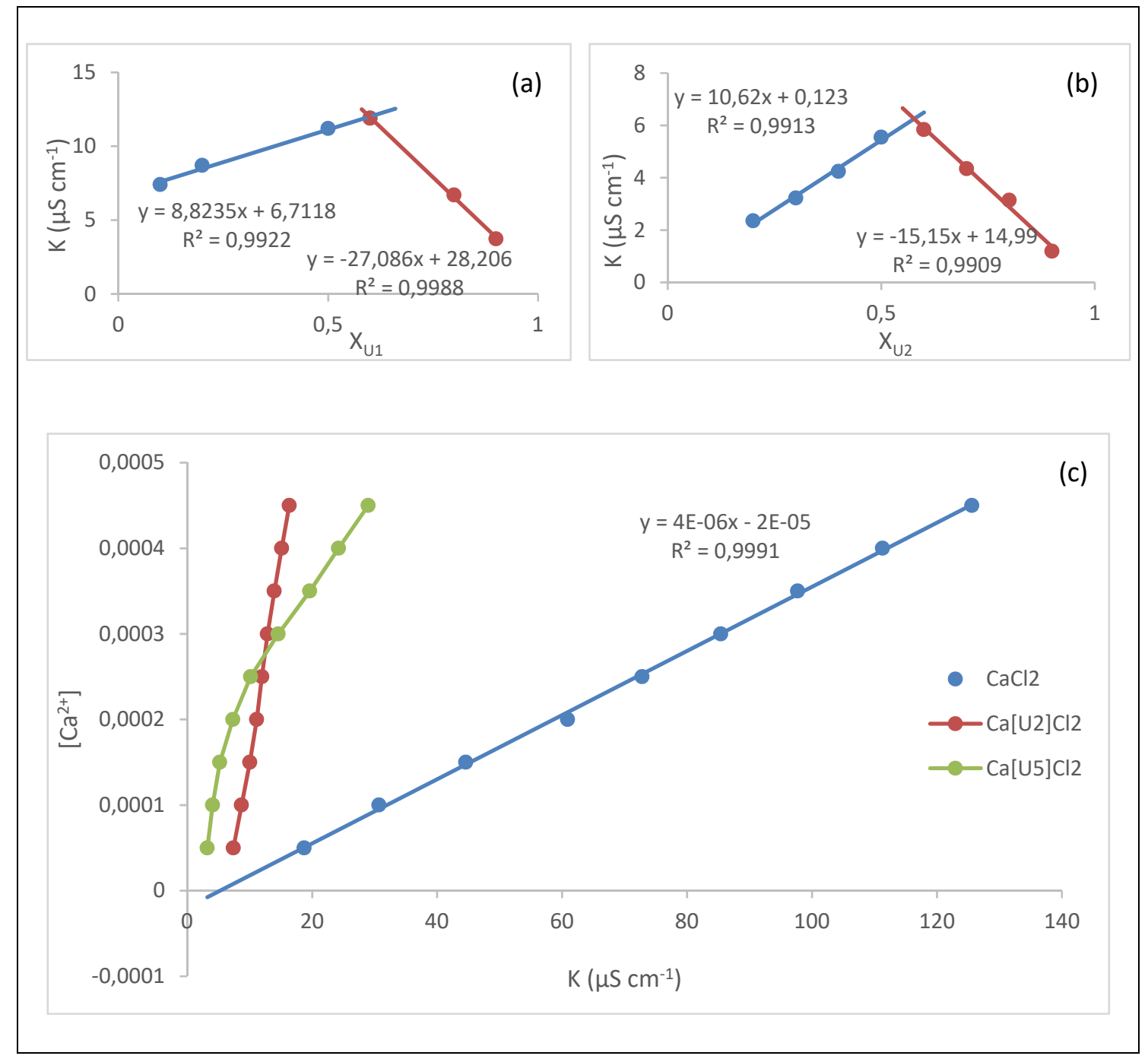

Şekil $5.25{ }^{\circ} \mathrm{C}$ da $\% 50$ asetonitril/su içerisinde (a) U1 ligantının, (b) U2 taç eterinin kalsiyum iyonu ile kompleksleşme oranının tespit edilmesi, (c) $\mathrm{CaCl}_{2}$ ile $U 1$ ve $U 2$ kompleksleri için gözlenen iletkenlik $\left(\mathrm{K}\left(\mu \mathrm{S} \mathrm{cm}^{-1}\right)\right)$ karşı $\left[\mathrm{Ca}^{2+}\right]\left(\mathrm{mol} \mathrm{L}^{-1}\right)$ iyonu değişimi grafikleri

$\mathrm{Ca}^{2+}$ iyonu ile yapılan kondüktometrik kompleksleşme çalışmasında kompleksleşme oranı hem U1 hem de U2 ligantları için 2/3 olarak tespit edilmiştir (Şekil $5 \mathrm{a}$-b). Kompleksleşme sabitleri incelendiğinde U1 taç eteri için $\log \mathrm{Ke}=17.79$ ve U2 taç eteri için $\log \mathrm{Ke}=12.18$ olarak tespit edilmiştir (Tablo 1). Hem U1 hem de U2 taç eterleri oldukça yüksek kompleksleşme göstermişlerdir (Şekil 5 c). 


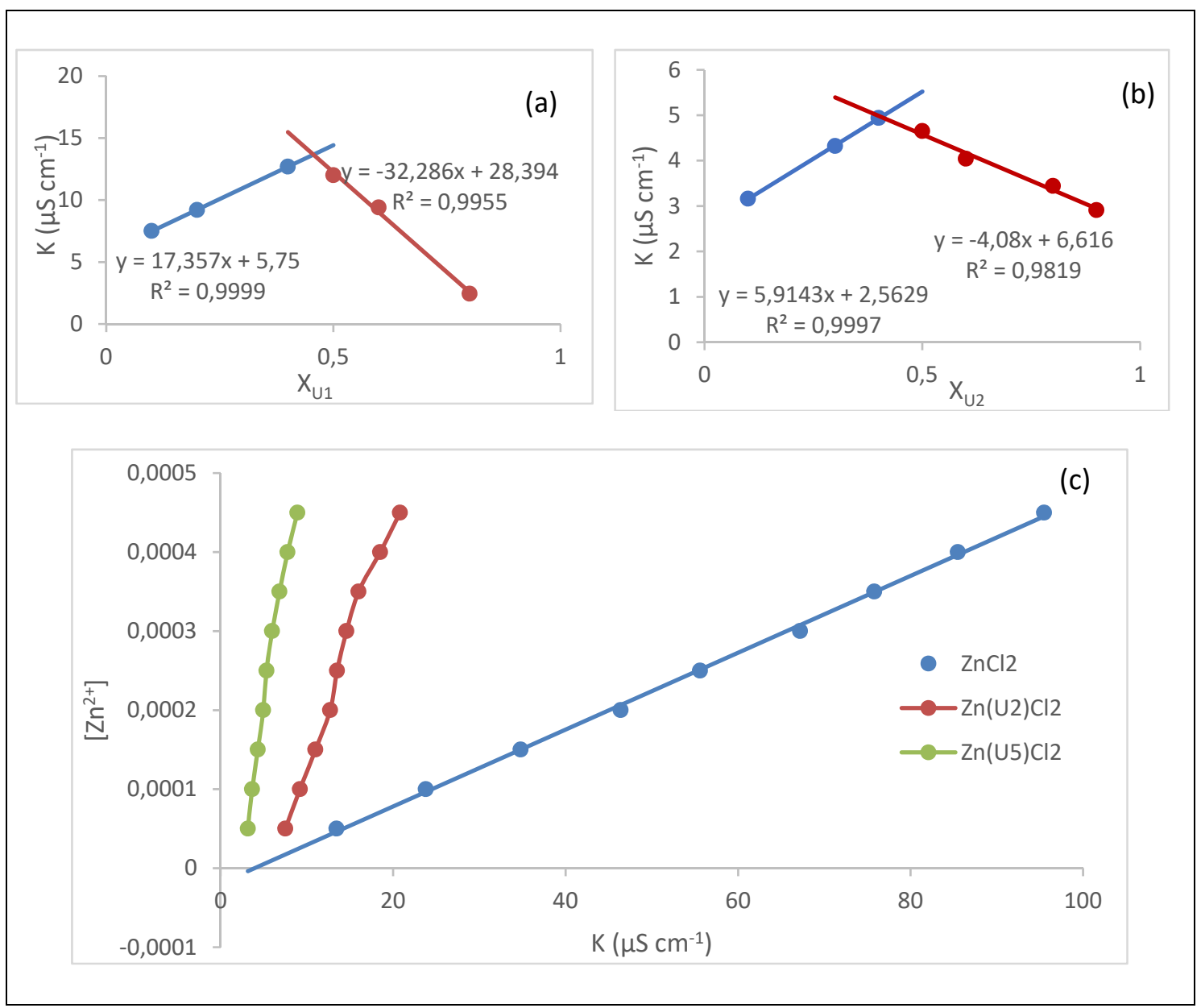

Şekil $6.25^{\circ} \mathrm{C}$ da \% 50 asetonitril/su içerisinde (a) U1 ligantının, (b) U2 taç eterinin çinko iyonu ile kompleksleşme oranının tespit edilmesi, (c) $\mathrm{ZnCl}_{2}$ ile $U 1$ ve $U 2$ kompleksleri için gözlenen iletkenlik $\left(\mathrm{K}\left(\mu \mathrm{S} \mathrm{cm}^{-1}\right)\right)$ karşı $\left[\mathrm{Zn}^{2+}\right]\left(\mathrm{mol} \mathrm{L}^{-1}\right)$ iyonu değişimi grafikleri

Çinko iyonu tiyo taç eter (U1) ve okso taç eter (U2) bileşikleri ile Şekil 6 a-b'de tespit edildiği gibi $3 / 2$ oranında kompleksleşme yapmıştır. Her iki bileşik de yüksek kompleksleşme göstermiştir. Ancak iki ligand kıyaslandığında okso taç eter olan U2 taç eterinin daha yüksek kompleksleşme sabitine sahip olduğu gözlenmektedir (log Ke: $18.71<20.34)$. 


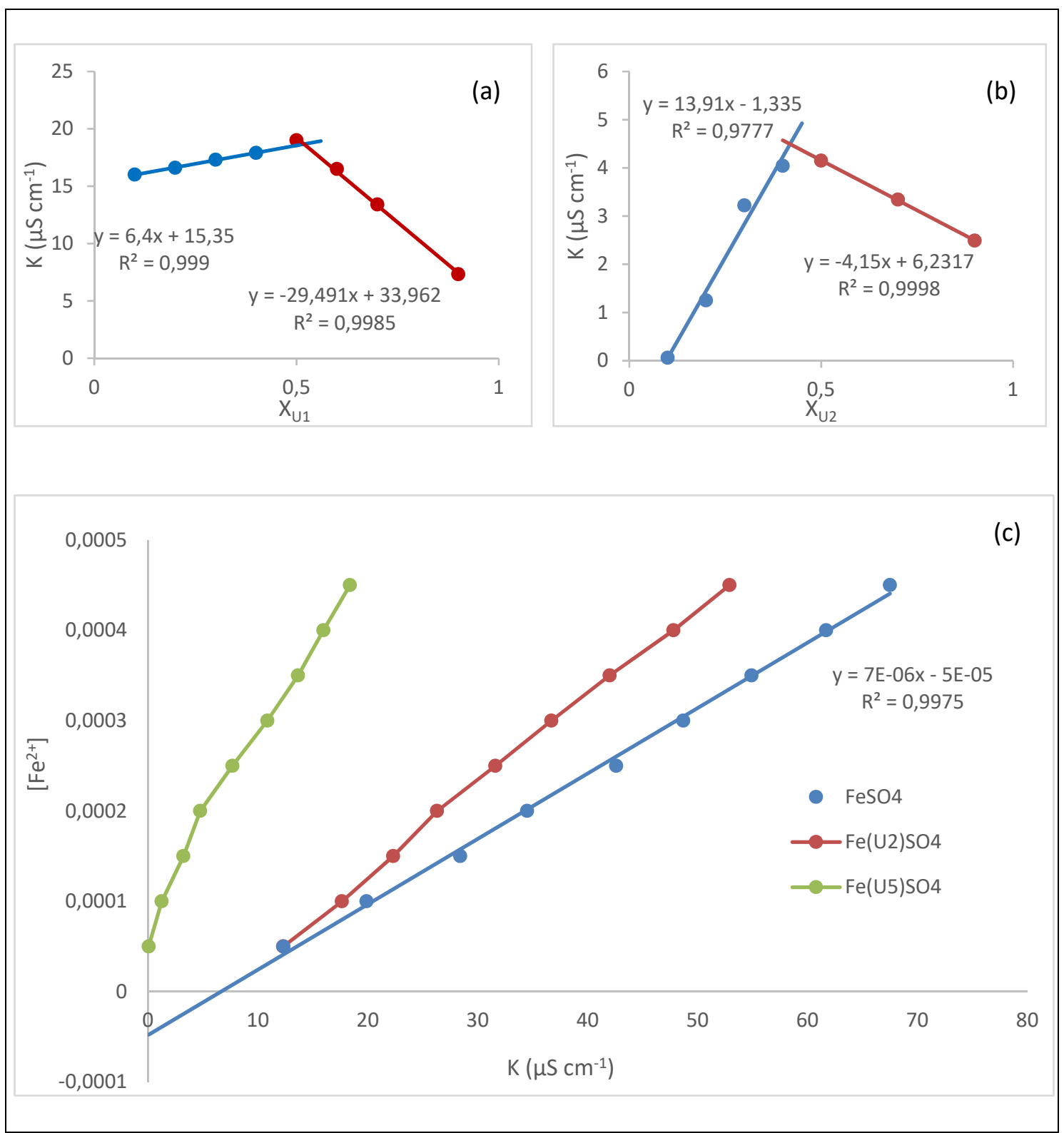

Şekil 7. $25^{\circ} \mathrm{C}$ da \% 50 asetonitril/su içerisinde (a) U1 ligantının, (b) U2taç eterinin demir iyonu ile kompleksleşme oranının tespit edilmesi, (c) FeSO 4 ile $U 1$ ve $U 2$ kompleksleri için gözlenen iletkenlik $\left(\mathrm{K}\left(\mu \mathrm{S} \mathrm{cm}^{-1}\right)\right)$ karşı $\left[\mathrm{Fe}^{2+}\right]\left(\mathrm{mol} \mathrm{L}^{-1}\right)$ iyonu değişimi grafikleri

Şekil 7 ve Tablo 1 incelendiğinde $\mathrm{Fe}^{2+}$ seçici olarak okso taç eter (U2) ile yüksek kompleksleşme gösterirken, tiyo taç eter (U1) ile oldukça düşük kompleksleşme göstermiştir. Kompleksleşme oranları ise sırasıyla $1 / 1$ ve $3 / 2$ 'dir. Kompleksleşme oranının artması kompleksleşmeyi de artırmaktadır. Okso taç eterin boşluk çapının demir (II) iyonu ile uyumlu olması kompleksleşmenin artmasını sağlamıştır. 


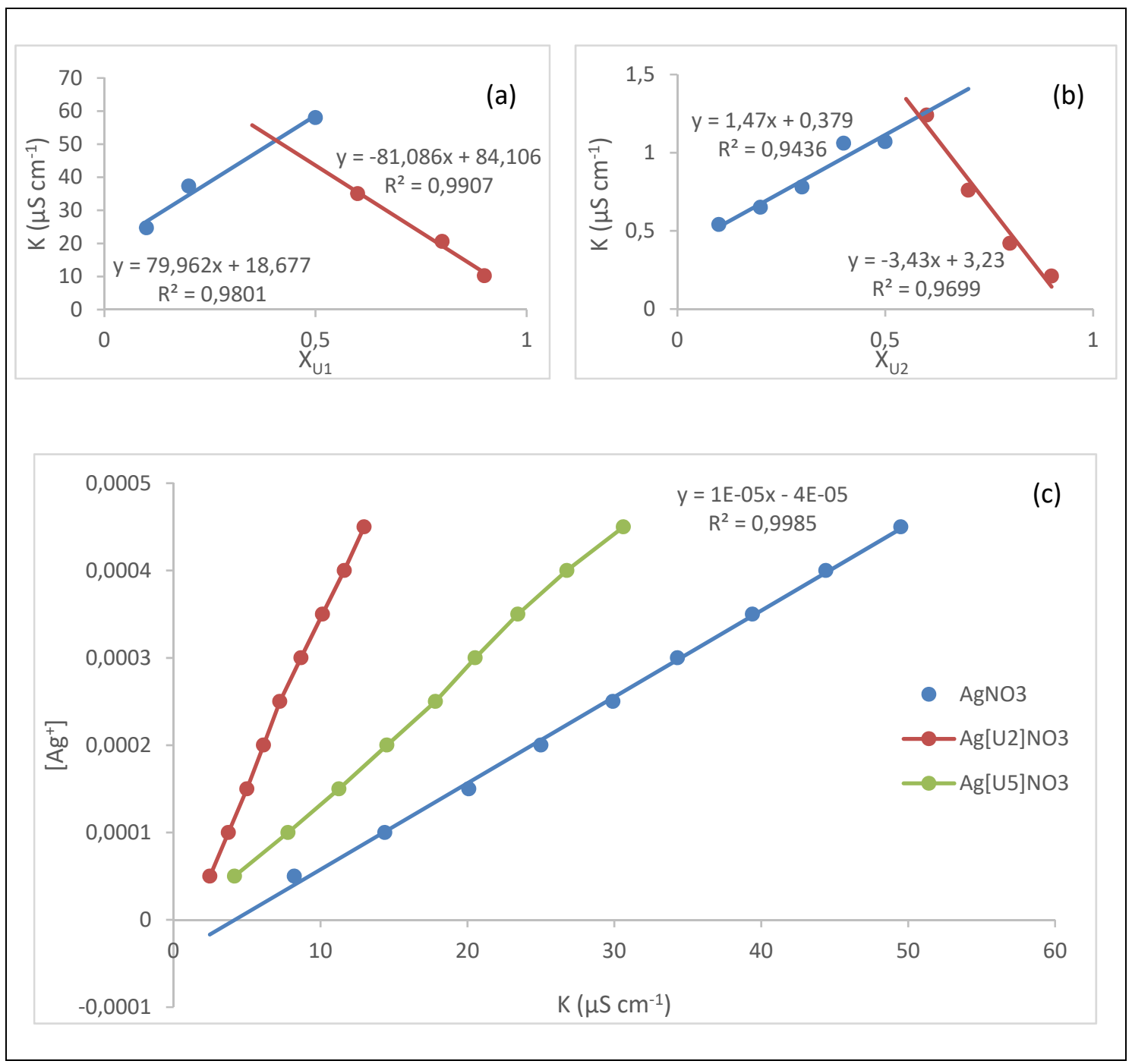

Şekil $8.25^{\circ} \mathrm{C}$ da $\% 50$ asetonitril/su içerisinde (a) U1 ligantının, (b) U2 taç eterinin gümüş iyonu ile kompleksleşme oranının tespit edilmesi, (c) $\mathrm{AgNO}_{3}$ ile $U 1$ ve $U 2$ kompleksleri için gözlenen iletkenlik $\left(\mathrm{K}\left(\mu \mathrm{S} \mathrm{cm}^{-1}\right)\right)$ karşı $\left[\mathrm{Ag}^{+}\right]\left(\mathrm{mol} \mathrm{L}^{-1}\right)$ iyonu değişimi grafikleri

Gümüş iyonları hem tiyo hem de okso taç eterlerle benzer kompleksleşme göstermiştir ( $\log \mathrm{Ke} \approx 14$ ). Ancak kompleksleşme oranları birbirinden farklıdır (sırasıyla U1 ve U2 için $3 / 2$ ve $2 / 3$, Tablo 1 ve Şekil 8 a-b). Bu durum bahsedildiği üzere tiyo taç eterde yer alan kükürt atomlarından kaynaklanmaktadır. Ayrıca Şekil 8 c'de artan gümüş konsantrasyonuna karşılık gözlenen iletkenlik değerleri grafik edilmiş ve tiyo taç eter olan U1'nin okso taç eter türevi olan U2'den daha çok kompleksleşme yaptı̆̆ gözlenmiştir. 
ÇIÇEK B., ÇALIŞIR Ü.

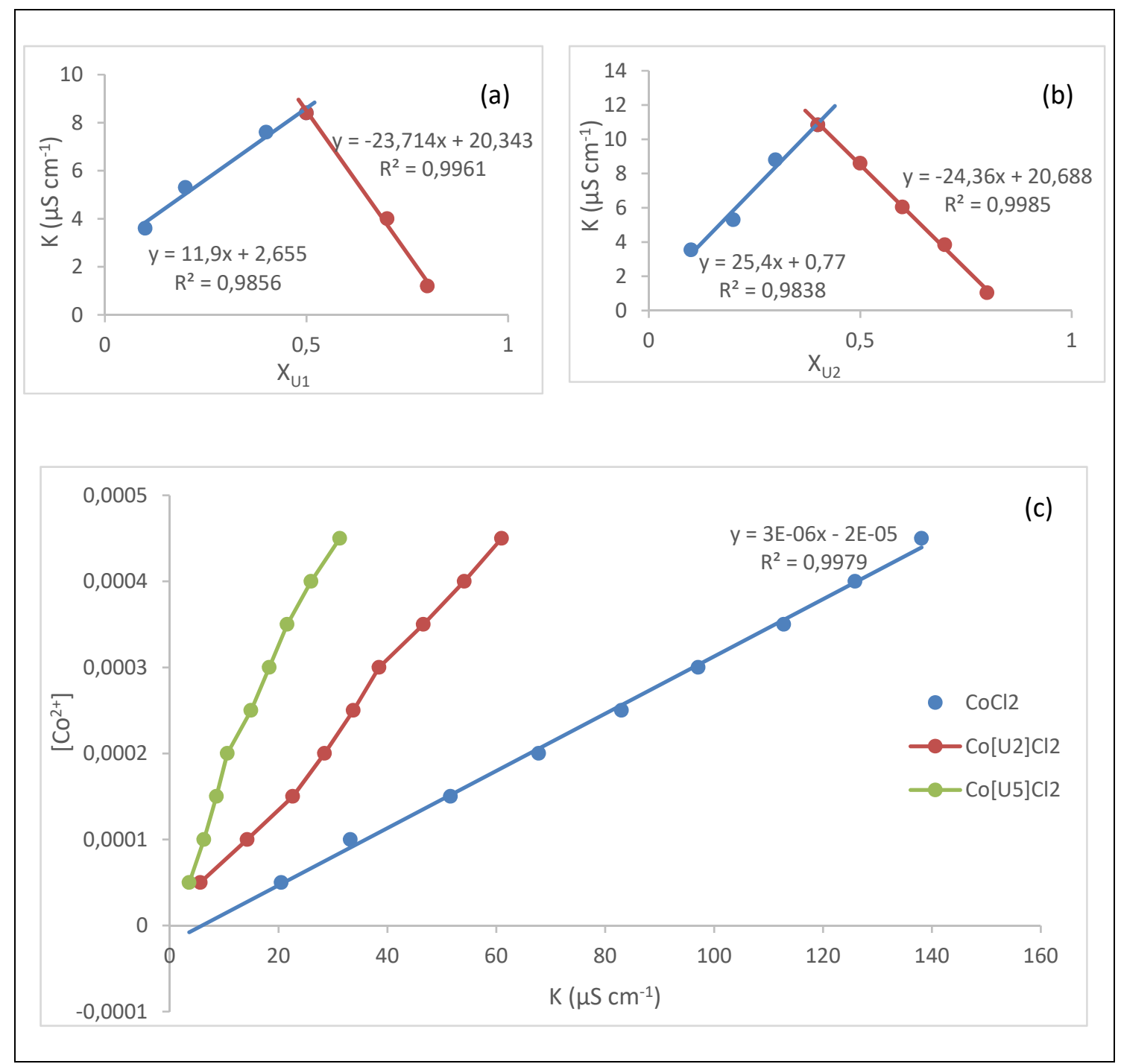

Şekil $9.25^{\circ} \mathrm{C}$ da \% 50 asetonitril/su içerisinde (a) U1 ligantının, (b) U2 taç eterinin kobalt iyonu ile kompleksleşme oranının tespit edilmesi, (c) $\mathrm{CoCl}_{2}$ ile $U 1$ ve $U 2$ kompleksleri için gözlenen iletkenlik $\left(\mathrm{K}\left(\mu \mathrm{S} \mathrm{cm}^{-1}\right)\right)$ karşı $\left[\mathrm{Co}^{2+}\right]\left(\mathrm{mol} \mathrm{L}^{-1}\right)$ iyonu değişimi grafikleri

Şekil 9'da verilen grafikler incelendiğinde kobalt iyonu ile U1'nin 1/1 oranında kompleksleştiği U2'in ise $3 / 2$ oranında kompleksleştiği gözlemlenmiştir. $\mathrm{Bu}$ kompleksleşme stokiyometrik katsayıları kullanılarak kompleksleşme sabitleri hesaplanmıştır. Kompleksleşme sabitleri kıyaslandığında U1'nin daha az kompleksleşme yaptığ1 $(\log \mathrm{Ke}=6.01)$ gözlemlenirken, U2'in kobalt iyonu ile kompleksleşmesinin oldukça fazla olduğu gözlemlenmiştir (log Ke=19.03). Bu durumu Şekil 9c desteklemektedir.

Bu çalışma kapsamında daha önceki çalışmamızda [9] sentezlediğimiz bileşikler (U1 ve U2) için komplekleşme sabitlerinin kondüktometri yöntemiyle belirlenmesi yapılmıştır. $\mathrm{Bu}$ amaçla ilk olarak Job's Plot yönteminin kondüktometriye uyarlanmasıyla kompleksleşme oranları tespit edilmiştir (Şekil 2-9 a-b). Daha önceki birçok metal/ligand kompleksleşme çalışmasında stokiyometrik katsayılar 1/1 oranında kabul edilmiş ve bir metalin bir ligand tarafından bağlandığı düşünülmüştür. Ancak bu çalışma kapsamında 1:1 (1/1) komplekslerin yanında sandviç komplekslerin $(2 / 1,1 / 2,2 / 3,3 / 2)$ oluşturduğu gözlenmiştir. Bu kompleksleşme oranlarının kullanılmasıyla kompleksleşme sabitleri $\mathrm{K}_{\mathrm{e}}$, 
Log $K_{e}$ ve $-\Delta G^{\theta}$ hesaplanmıştır (Tablo 1). Elde edilen sonuçlara göre seçilen U1 ve U2 bileşiklerinin $\mathrm{NaCl}, \mathrm{KCl}, \mathrm{MgCl}_{2} .6 \mathrm{H}_{2} \mathrm{O}, \mathrm{CaCl}_{2} .2 \mathrm{H}_{2} \mathrm{O}, \mathrm{ZnCl}_{2}, \mathrm{FeSO}_{4} .7 \mathrm{H}_{2} \mathrm{O}, \mathrm{AgNO}_{3}$, $\mathrm{CoCl}_{2} .8 \mathrm{H}_{2} \mathrm{O}$ metal tuzlarıyla kompleks oluşturdukları gözlenmiştir.

Tablo 1. U1 ve U2 taç eteri ile bazı katyonların kompleksleşme oranları, kompleksleşme sabitleri ve serbest Gibbs enerjileri

\begin{tabular}{|c|c|c|c|c|c|}
\hline Taç Eter & Katyon & $\begin{array}{c}\text { Kompleksleşme } \\
\text { Oranı } \\
\left(\mathbf{n}_{\text {tuz }} / \mathbf{n}_{\text {ligand }}\right)\end{array}$ & Ke & $\log K_{e}$ & $-\Delta \mathbf{G}^{\boldsymbol{\theta}}$ \\
\hline \multirow{8}{*}{ U1 } & $\mathrm{Na}^{+}$ & $3 / 2$ & $1.43 \times 10^{+19}$ & 19.16 & 26117.79 \\
\hline & $\mathrm{K}^{+}$ & $2 / 3$ & $7.41 \times 10^{+13}$ & 13.87 & 18910.93 \\
\hline & $\mathrm{Mg}^{2+}$ & $1 / 1$ & $2.29 \times 10^{+6}$ & 6.36 & 8672.45 \\
\hline & $\mathrm{Ca}^{2+}$ & $2 / 3$ & $6.17 \times 10^{+17}$ & 17.79 & 24256.17 \\
\hline & $\mathrm{Zn}^{2+}$ & $3 / 2$ & $5.18 \times 10^{+18}$ & 18.71 & 25515.60 \\
\hline & $\mathrm{Fe}^{2+}$ & $1 / 1$ & $5.23 \times 10^{+4}$ & 4.71 & 6432.919 \\
\hline & $\mathrm{Ag}^{+}$ & $3 / 2$ & $2.57 \times 10^{+14}$ & 14.41 & 19647.40 \\
\hline & $\mathrm{Co}^{2+}$ & $1 / 1$ & $1.03 \times 10^{+6}$ & 6.01 & 8198.47 \\
\hline \multirow{8}{*}{ U2 } & $\mathrm{Na}^{+}$ & $1 / 1$ & $1.83 \times 10^{+19}$ & 19.26 & 26265.58 \\
\hline & $\mathrm{K}^{+}$ & $2 / 3$ & $1.36 \times 10^{+19}$ & 19.13 & 26087.36 \\
\hline & $\mathrm{Mg}^{2+}$ & $1 / 1$ & $8.88 \times 10^{+4}$ & 4.94 & 6746.77 \\
\hline & $\mathrm{Ca}^{2+}$ & $2 / 3$ & $1.52 \times 10^{+12}$ & 12.18 & 16609.19 \\
\hline & $\mathrm{Zn}^{2+}$ & $3 / 2$ & $2.19 \times 10^{+20}$ & 20.34 & 27733.63 \\
\hline & $\mathrm{Fe}^{2+}$ & $3 / 2$ & $2.17 \times 10^{+19}$ & 19.33 & 26366.39 \\
\hline & $\mathrm{Ag}^{+}$ & $2 / 3$ & $2.05 \times 10^{+14}$ & 14.31 & 19512.58 \\
\hline & $\mathrm{Co}^{2+}$ & $3 / 2$ & $1.07 \times 10^{+19}$ & 19.03 & 25946.86 \\
\hline
\end{tabular}

Elde edilen kompleksleşme verileri değerlendirildiğinde U1 ile en yüksek kompleksleşme $\mathrm{Na}^{+}$iyonu ile gerçekleşmiştir $(\log \mathrm{Ke}=19.16)$. U1 taç eteri en düşük kompleksleşme ise $\mathrm{Fe}^{2+}$ iyonu ile olduğu gözlenmiştir $(\log \mathrm{Ke}=4.71)$. En yüksek kompleksleşmeden en düşük kompleksleşmeye doğru sıraladığımızda $\mathrm{Na}^{+}>\mathrm{Zn}^{2+}>\mathrm{Ca}^{2+}>\mathrm{Ag}^{+}>\mathrm{K}^{+}>\mathrm{Mg}^{2+}>$ $\mathrm{Co}^{2+}>\mathrm{Fe}^{2+}$ şeklindedir (sırasıyla $\log \mathrm{Ke}=19.16>18.71>17.79>14.41>13.87>6.36$ $>6.01>4.71)$. U2 taç eteri için $\mathrm{Na}^{+}, \mathrm{K}^{+}, \mathrm{Zn}^{2+}$ ve $\mathrm{Co}^{2+}$ iyonları en yüksek kompleksleşmeye sahiptir. En az kompleksleşme yapan iyon $\mathrm{Mg}^{2+}$ iyonudur. En yüksek kompleksleşmeden en düşük kompleksleşmeye doğru sıraladığımızda $\mathrm{Zn}^{2+}>\mathrm{Fe}^{2+}>\mathrm{Na}^{+}$ $>\mathrm{K}^{+}>\mathrm{Co}^{2+}>\mathrm{Ag}^{+}>\mathrm{Ca}^{2+}>\mathrm{Mg}^{2+}$ şeklindedir (sırasiyla $\log \mathrm{Ke}=20.34>19.33>19.26$ $>19.13>19.03>14.31>12.18>4.94)$.

Bu çalışmadan elde edilen veriler daha önceki çalışmamızda sıvı-sıvı iyon çiftleri metal ekstraksiyonu ile elde edilen veriler ile çoğunlukla benzerdir. Job's Plot yöntemiyle kompleksleşme stokiyometrilerin tespit edilmesi, gerçek kompleksleşme sabitlerinin hesaplanmasına olanak sağlamıştır. Benzo tiyo taç eter (U1) bileşiğinde hacimli kükürt atomlarının sayısının fazla olması ve konformasyonu sebebiyle geçiş metallerine olan ilgisi benzo-okso taç eter (U2) bileşiğinden daha düşüktür. 


\section{Kaynaklar}

[1] Zhou, Q.Z., He, C.L., Gu, H.N., Miao, Q.M., Zhai, C.X., Convenient synthesis of aryl-incorporated ditosylates and their application in preparation of crown ethers with higher yield, Chinese Chemical Letters, 19, 911-914, (2008).

[2] Pedersen, C.J., Cyclic Polyethers and Their Complexes with Metal Salts, Journal of the American Chemical Society, 89, 10, 2495-2496, (1967).

[3] Pedersen, C.J., Macrocyclic Polyethers: Dibenzo-18-Crown-6 Polyether and Dicyclohexyl-18-Crown-6 Polyether, Organic Syntheses, 52, 66, (1972).

[4] Pedersen, I.S., Prize, N., Crown, C.E., Chapter 2 Crown Ethers, 10, 34-54, (1987).

[5] Parker, D., Macrocycle Compounds-Synthesis, II. Series, Oxford University Press, New York, 1996.

[6] Water, L.G.A.V., Driessen, W.L., Glenny, M.W., Reedijk, J., Schröder, M., Selective and reversible extraction of heavy metal-ions by mixed-donor crown ether-modified oxirane and thiirane resins, Reactive and Functional Polymers, 51, 33-47, (2002).

[7] Yordanov, A.T., Roundhill, D.M., Solution extraction of transition and posttransition heavy and precious metals by chelate and macrocyclic ligands, Coordination Chemistry Reviews, 170, 93-124, (1998).

[8] Lu, T., Wang, X., Tan, M., Liu, Y., Inoue, Y., Hakushi, T., Studies on rare-earth complexes with crown ethers. Part XXV. Synthesis, characterization, and structure of the complexes of lanthanite nitrates with 13-crown-4, Helvetica Chimica Acta, 76, 241-247, (1993).

[9] Bruening, R.L., Tarbet, B.J., Krakowiak, K.E., Bruening, M.L., Izatt, R.M., Bradshaw, J.S., Quantitation of cation binding by silica gel bound thiamacrocycles and the design of highly selective concentration and purification columns for palladium(II), gold(III), silver(I), and mercury(II), Analytical Chemistry, 63, 1014-1017, (1991).

[10] Çiçek, B., Çakir, Ü., Azizoglu, A., The associations of macrocyclic ethers with cations in 1,4-dioxane/ water mixtures; Potentiometric $\mathrm{Na}^{+}$and $\mathrm{K}^{+}$binding measurements and computational study, Journal of Inclusion Phenomena and Macrocyclic Chemistry, 72,121-125, (2012).

[11] Çakir, Ü., Çiçek, B., Yildiz, Y.K., Alkan, M., Solvent effect upon 1on-pair extraction of different sodium dyes using some crown ethers, Journal of Inclusion Phenomena and Macrocyclic Chemistry, 34, 153-165, (1999).

[12] Çiçek, B., Onbaşıŏlu, Z., Synthesis and characterization of 1,3,4-thiadiazole-2,5dithio crown ethers, Heterocyclic Communication, 22, 329-332, (2016).

[13] Çakir, Ü., Çiçek, B., Extraction-ability and -selectivity of tetra-aza-crown ethers for transition metal cations, Transition Metal Chemistry, 29, 263-268, (2004).

[14] Çiçek, B., Çalışır, Ü., The investigation of complexation properties and hard-soft acid-base relationship between thiacrown ethers and metal ions, Letters in Organic Chemistry, 13, 572-577, (2016).

[15] Çalışır, Ü., Benzo-tiyo crown eterlerin sentezi ve ekstraktif özelliklerinin incelenmesi, Yüksek Lisans Tezi, Balıkesir Üniversitesi, Fen Bilimleri Enstitüsü, Balıkesir, 2014.

[16] Calisir, U., Çiçek, B., Comparison of classic and microwave-assisted synthesis of benzo-thio crown ethers, and investigation of their ion pair extractions, Journal of Molecular Structure, 1148, 505-511, (2017).

[17] Çiçek, B., Yıldız, A., Synthesis, Metal ion complexation and computational studies 
of thio oxocrown ethers, Molecules, 16, 8670-8683, (2011).

[18] Litvinova, V.V., Anisimov, A.V., Thiacrown compounds: synthesis and properties, Chemistry of Heterocyclic Compounds, 35, 12-22, (1999).

[19] Çiçek, B., Çalışır, Ü., Bazı karbazol schiff bazlarının katyon bağlama özelliklerinin kondüktometrik incelenmesi, Balıkesir Üniversitesi Fen Bilim. Enstitüsü Dergisi, 19, 246-256 (2017).

[20] Çiçek, B., Synthesis of tetra-aza coronands and determination of complexity capabilities by potentiometric, conductometric and liquid-liquid extraction methods, PhD Thesis, Balikesir University, Institute of Science and Technology, Balikesir, 2002.

[21] Çiçek, B., Çakır, Ü., Erk, Ç., The determination of crown-cation complexation behavior in dioxane/water mixtures by conductometric studies, Polymers for Advanced Technologies, 836, 831-836, (1998).

[22] Erk, Ç., Cakir, U., Cicek, B., Estimation of $\mathrm{Li}^{+}, \mathrm{K}^{+}$and $\mathrm{Ca}^{2+}$ complexation with 12 crown- 4,15 crown-5 and 18 crown- 6 using a Na ${ }^{+}$ISE in dioxane-water, part IV Cation equilibrium constants of macrocyclic ethers with ion selective electrodes, Mikrochimica Acta, 132, 79-82, (1999).

[23] Çakir, Ü., Çiçek, B., Erk, Ç., The associaton constants of macrocyclic ether-cation interections in dioxane / water mixtures, part II, Journal of Inclusion Phenomena and Macrocyclic Chemistry, 275-278, (1998).

[24] Job, P., Formation and stability of inorganic complexes in solution., Annali di Chimica, 9, 113-203, (1928).

[25] Yang, L., Zhu, W., Fang, M., Zhang, Q., Li, C., A new carbazole-based Schiffbase as fluorescent chemosensor for selective detection of $\mathrm{Fe}^{3+}$ and $\mathrm{Cu}^{+}$, Spectrochimica Acta Part A: Molecular and Biomolecular Spectroscopy, 109, 186-92, (2013).

[26] Nabeshima, T., Tsukada, N., Nishijima, K., Ohshiro, H., Yano, Y., Remarkably selective $\operatorname{Ag}(+)$ extraction and transport by thiolariat ethers., The Journal of Organic Chemistry, 61, 4342-4350, (1996).

[27] Huang, C.Y., Determination of binding stoichiometry by the continuous variation method: The Job Plot, Methods in Enzymology, 87, 509-525, (1982).

[28] Ijeri, V.S., Srivastava, A.K., Complexation of macrocyclic compounds with mono, di- and tri-valent transition and heavy metal ions in 90\% (v/v) DMSO + water medium, Polyhedron, 22, 569-574, (2003). 